\title{
Correlates of Public Kindergarten Teachers' Self-efficacy and Their Developmentally Appropriate Practice Beliefs in Selected Districts in the Central Region, Ghana
}

\author{
Winston Kwame Abroampa ${ }^{1 *} \quad$ Selina Nana Simpson ${ }^{2}$ \\ 1.Faculty of Educational Studies, Kwame Nkrumah University of Science and Technology, Kumasi \\ 2.Department of Early Childhood Education, University of Education, Winneba
}

\begin{abstract}
The study examined relationships between Kindergarten Teachers' Self-efficacy and their Developmentally Appropriate Practice (DAP) beliefs in selected pubic basic schools in two Districts in the Central Region, Ghana. The study was underpinned by Bandura's Social Cognitive Theory. The cross-sectional survey design was adopted for the study. Simple Random and Purposive sampling techniques were used in selecting the districts and kindergarten teachers. The sample size for the study was 274 kindergarten teachers, data analysis was however based on responses from 264 of them. An adaption of the long version of Tschannen Moran and Hoy Self-efficacy scale and self developed items from the 12 principles of DAP were used to gather data. Means, Pearsons Product Moment Correlation Coefficient and Standard Multiple Regression were used in analyzing data. The findings revealed that kindergarten teachers' beliefs in employing DAP in kindergarten settings was high. There was a small but positive statistically significant correlation between kindergarten teachers' self-efficacy and their developmentally appropriate practice beliefs. It also came to light that, of the three self-efficacy sub-variables, kindergarten teachers' self-efficacy in instructional strategies was the strongest predictor of their developmentally appropriate practice beliefs. It was recommended that stakeholders should organize workshops, seminars, for kindergarten teachers to enable them become abreast with current trends that would increase their self-efficacy and also their belief in their ability to use DAP.
\end{abstract}

Keywords: kindergarten, self-efficacy, developmentally appropriate practice, beliefs

DOI: $10.7176 / \mathrm{JEP} / 11-14-06$

Publication date:May $31^{\text {st }} 2020$

\section{Introduction}

Early Childhood Education plays an essential role in fostering children's development and prepares them for success for the rest of their academic years and beyond. It gives every child the best start in life and also helps young children to develop capabilities and potentials in the social, physical, intellectual, creative and emotional faculties. Lenroot and Giedd (2006) intimate that, from infancy, children undergo unimaginable development and by the time they enter kindergarten, their brains have already developed about $90 \%$ of its capacity. This phenomenal development is harnessed by the nurturing home and school environment young children, who eventually become early learners find themselves in.

Bartels (2004) opines that children who go through early childhood education are likely to stay longer in education during which period the teacher teaches the child to create, make and construct using Legos, clay, bricks and other resources; these early experiences have enormous benefits which are replete in literature. The numerous documented benefits of early childhood education have precipitated the reforms in many countries across the globe including Ghana. In 2007, the Government of Ghana added two-year kindergarten education to basic education thereby increasing basic education from nine (9) years to eleven (11) years. In Ghana, kindergarten education is part of early childhood education provided for children between ages four and five. To make kindergarten education effective and relevant there is the need to employ teachers with the requisite skills and in-depth understanding of how the child develops and learns using developmentally appropriate practices.

\section{Developmentally Appropriate Practice}

The first definitive position on Developmentally Appropriate Practice (DAP) was adopted by the National Association for the Education of Young Children in 1998. Gestwicki (2007) explained DAP as applying child development knowledge in making thoughtful and appropriate decisions about early childhood programme practices. This is a corollary of Bredekamp and Copple's (1997) earlier position that "programs designed for young children be based on what is known about young children"(p.v). The conversation around DAP later developed into a framework designed to promote young children's optimal learning and development. It involves teachers meeting young children where they are, both as individuals and as part of a group; and helping each child meet challenging and achievable learning goals (Cochran, 2007). Children are active learners and through interactions with teacher, adults, peers, environment, and solving conflicts, they construct meaningful knowledge. Therefore, employing DAP requires teachers to provide a conducive environment and offering content, materials, activities, 
and methodologies that are consistent with a child's level of development and for which the individual child is ready (Bredekamp, 2000). Developmentally appropriate classrooms set up by teachers can meet the needs of an individual child, promote self-esteem and positive feelings of children towards school. Such practices are thus considered ideal and critical to the effective implementation of any kindergarten curriculum.

The National Association for the Education of Young Children (2009) notes that DAP hinges on three core considerations that constitute knowledge that are critical components in making good decisions for children in any learning environment. These are child development appropriateness; Individual appropriateness; and Social and cultural appropriateness.

Teachers who work with young children are required to make decisions in the classroom by combining their knowledge of child development with an understanding of the individual child to achieve desired and meaningful outcomes. More so, since children do not grow up in isolated areas, but rather, within families, neighborhoods, and communities, it is important that teachers have knowledge of the social and cultural contexts in which children live in order to ensure that learning experiences are meaningful and relevant for the participating children and their families.

Simply, DAP suggests the use and application of the knowledge and information about young children in planning curricula and learning. This implies the selection and use of resources techniques and strategies that are age appropriate and relevant in supporting young children's learning. Gestwicki, (2007) intimates that age appropriateness stems from the knowledge of age-related human characteristics that permits general predictions within an age range about what activities, materials, interactions, or experiences will be safe, healthy, interesting, achievable, and also challenging to children. Activities, routines, and expectations are designed so that they accommodate and compliment the characteristics of children within a general age-range (Kostelnik, Soderman \& Whiren, 2004).

From the core considerations indicated above, what have become popularly known as the twelve (12) DAP principles guiding the development and implementation of any early childhood education curriculum were espoused by Bredekamp and Copple (1997) and adopted by NAEYC (2009). These are;

1. All domains of children's development: physical, social, emotional, and cognitive are important and they are closely interrelated.

2. Many aspects of children's learning and development follow well- documented sequences, with later abilities, skills, and knowledge building on those already acquired.

3. Development and learning proceed at varying rates from child to child as well as at uneven rates across different areas of each child's individual functioning.

4. Development and learning result from a dynamic and continuous interaction of biological maturation and experience.

5. Early experiences have profound effects, both cumulative and delayed, on a child's development and learning.

6. Development goes from the simpler to the more complex and difficult in all domains or areas of learning.

7. Children develop best when they have secure, consistent relationships with responsive adults and opportunities for positive relationships with peers.

8. Children grow and learn in a number of social and cultural contexts such as family, community, religion, school etc. They are shaped by these things.

9. Children are always active in their minds and trying to understand their world. Therefore, a wide variety of teaching approaches and ways of being together is best for learning.

10. Play provides an important way to build thinking, language and, most importantly, social skills.

11. Development and learning happen best when children have a challenge that is just beyond where their skills are at the moment.

12. Children's challenging and successful experiences shape their motivation to learn.

These principles highlight how individual variation in development and learning should be linked to decisions about the curriculum, teaching and interactions to ensure that teaching decisions take account of the uniqueness of each child as well as group differences in temperament, growth rate, personality and background. A gleaning of the foregoing suggests that effective teaching in the kindergarten requires content knowledge of child development - a deep understanding of developmentally appropriate expectations, knowing the way young children think and behave, and why (Allen \& Kelly, 2015). The assumption is that practitioners who are versatile and have an appreciable level of belief that they can promote learning among young children will explore varying sources and resources that are developmentally appropriate to ensure that learning is effected.

\section{Bandura's Social Cognitive Theory}

Employing developmentally appropriate practices in a kindergarten setting requires an effective $\mathrm{KG}$ teacher or early childhood practitioner. One variable which has consistently been associated with the qualities of an effective teacher is teacher self-efficacy. Teacher self-efficacy is a teachers' confidence or belief in his/her ability to promote 
children's learning (Hoy, 2000). The self-efficacy concept evolved from the social cognitive theory espoused by Albert Bandura. The thrust of Bandura's social cognitive theory is the concept of self-efficacy which is originally explained as a specific type of expectancy related to one's beliefs about their ability to perform a specific behaviour or set of behaviours required to produce a certain outcome (Bandura, 2006). However, the concept was extended to people's beliefs about their ability to exercise control over events that affect their lives and was further stretched to embrace the beliefs in their capabilities to mobilize the motivation, cognitive resources and course of action needed to exercise control over task demands. Self-efficacy was, therefore, not just self-judgment of what one could do with whatever skills one possessed but more specifically, it was a perceived self-efficacy of people's beliefs about their capabilities to produce designated levels of tasks (Basikin, 2008). They study thus takes a cue from the latter.

It is therefore expected that efficacious people (kindergarten teachers) would keep on trying, and exploring alternative when they experience difficulties with handling young children. Efficacious kindergarten teachers will, in spite of the kindergarten setting in which they find themselves, explore opportunities that will enable them employ developmentally appropriate practices to promote learning. If a teacher establishes a goal and strongly believes in his or her actions, it will lead to the success of that goal and also produce more effective coping strategies and higher levels of achievement. It is therefore expected that Kindergarten teachers' who have a high self-efficacy and are able to use developmentally appropriate practices are likely to have children in the classroom who learn. They have the ability to make changes in the learning milieu and use appropriate and differentiated innovative interactive techniques and strategies to promote learning of children in diverse contexts.

In Ghana, there have been concerns about early learners' competencies in numeracy and literacy as evident in Early Grade Reading Assessment (EGRA) and Early Grade Mathematics Assessment (EGMA) reported by the National Education Assessment Unit (2016). According to Boateng and Sekyere (2017) one major cause of low literacy, numeracy and low achievements among learners in Ghana that stakeholders normally overlook is the quality of and access to kindergarten education. Many researchers have tried to connect the low quality of kindergarten education to paucity of logistics, infrastructure, and trained, experienced, and committed kindergarten teachers (Gbate, 2011). Relatedly, Abroampa (2016; 2018) has intimated that most kindergarten teachers are either non-professionals or para-professionals who lack the requisite skills, competencies and wherewithal to apply developmentally appropriate practices in early childhood settings. As a result, their teaching practices are geared towards direct instruction, rote memorization activities, and other inappropriate strategies.

More so, one basic area that affects the successful development of teachers are their beliefs systems and the application of those belief systems in the classroom (Abroampa, 2016). The beliefs of teachers' affect how they transfer knowledge to children as well as apply developmentally appropriate practices in the classroom. He further contends that professional and experienced teachers have been found to have high self-efficacy in handling children than their unprofessional and novice counterparts, this is because as teachers develop their expertise, curricular practices are refined and self-efficacy is enhanced. It therefore seems that teacher self-efficacy has critical implications for curriculum implementation and can spell the success or failure of any educational reform (Hitchens-Smith, Ortlieb, \& Cheek, 2011).

In Ghana, there are many untrained kindergarten teachers, inequitable allocation of educational resources to urban and rural schools coupled with a high number of children in the kindergartens due to social interventions such as the Free School Feeding Programme. These conditions require kindergarten teachers with an appreciable level of self-efficacy who belief they can use developmentally appropriate practices in early childhood settings. It is against this backdrop that the study sought to examine the corelates of kindergarten teachers' self-efficacy and their developmentally appropriate practices beliefs in kindergartens in selected districts in the Central Region, Ghana.

The study sought to answer the following questions:

- What is kindergarten teachers' self-efficacy in employing developmentally appropriate practices in kindergartens?

- What is the relationship between kindergarten teachers' self-efficacy and their use of developmentally appropriate practices in kindergartens?

- How well do the self-efficacy sub-variables predict KG teachers' use of developmentally appropriate practice?

The framework below illustrates the interaction among the teacher self-efficacy sub-variables and developmentally appropriate practice beliefs. 


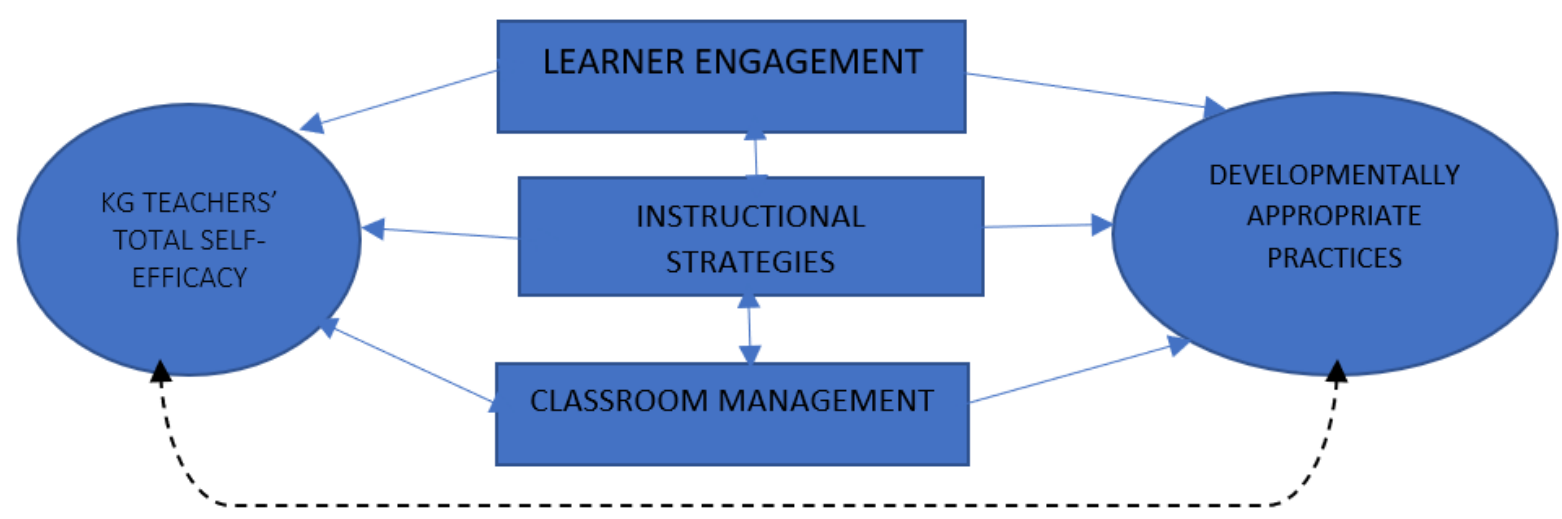

Figure 1: Conceptual framework

Figure 1 illustrates the interactions among total self-efficacy of KG teachers, its sub-variables of learner engagement, instructional strategies and classroom management and developmentally appropriate practice. The study hypothesized that there will be a significant relationship between KG teachers' total self-efficacy and their developmentally appropriate practice beliefs. This implied that a KG teacher with the belief that they can effect learning in kindergarten settings should be able to apply developmentally appropriate practices. It is also assumed that the three sub-variables will contribute varyingly and thus be able to predict the extent to which KG teachers are able to use developmentally appropriate practices in KG settings.

\section{Methods}

In this study data was collected on kindergarten teachers' self-efficacy and their developmentally appropriate practices beliefs at a particular point in time, focusing on studying and drawing inferences from public basic schools in selected districts in the Central Region, Ghana. Therefore, the cross-sectional survey design was adopted for the study. The design was employed to help produce a good amount of responses from a wide range of kindergarten teachers in public school. This permitted the gathering of enough data to determine the nature of the group studied as it existed at the time of the study.

The target population for the study was all kindergarten teachers in Central Region teaching in public basic schools whiles the accessible population was kindergarten teachers from two (2) randomly selected districts from the twenty (20) districts in the Central Region. Simple random sampling, and purposive sampling techniques were use in the study. Simple random sampling was used to select two districts out of the 20 districts for the study. The two districts selected eventually were the Gomoa West District and Cape Coast Metropolis with 74 and 137 public kindergartens respectively. Purposive sampling was used in selecting the class teachers in kindergartens 1 and 2 in all public basic schools in the selected districts. In all, a total of 274 kindergarten teachers were finally sampled for the study. This was because by virtue of their training and experience gained from teaching early learners and also in implementing the same curriculum, they are able to provide relevant responses required. In Ghana, there are two kindergarten classes (KG 1 and 2). Each class has a substantive teacher who may have attendants assisting them depending on the size or number of pupils in the class.

A four-point Likert-type scale questionnaire developed from Tschannen Moran and Hoy's long version of the Teacher Self-Efficacy Scale (TSES) with 22 items covering three sub-variables-learner engagement, instructional strategies, and classroom management was used. It was used together with a self-designed scale for Developmentally Appropriate Practice beliefs (DAP) generated from the 12 principles. In constructing these additional items to augment the TSES, the guidelines prescribed by Bandura (2006) were followed. Based on Bandura's social cognitive theory, teacher self-efficacy may be conceptualized as individual teachers' beliefs in their own ability to plan, organize, and carry out activities that are required to attain given educational goals. Following this conceptualization it is recommended that: (a) because self-efficacy is concerned with perceived capability the items should contain verbs like "can" or "be able to" in order to make clear that the items ask for mastery expectations because of personal competence, (b) the object in each statement should be "I" since the aim is to assess each teacher's subjective belief about his or her own capability, and (c) each item should contain a barrier. The latter point is underscored by Bandura's (2006) statement that if there were no obstacles to surmount, the activity would be considered easy to perform and everyone would be perceived to have high efficacy.

The questionnaire was pretested in 20 public kindergartens in the Effutu Municipality to determine the overall reliability of the research instrument using Cronbach's alpha to ascertain the internal consistency which yielded a reliability index of .874 . The questionnaires were administered by trained research assistants who spent about four weeks on the field after seeking permission from gate keepers and explaining purpose of the study. Two hundred and seventy-four (274) questionnaires were administered and a total of 264 retrieved representing $90 \%$. Data were analysed using a means for research question one, Pearsons Product Moment Correlation and Standard Multiple 
Regression to answer research questions two and three respectively.

\section{Data Presentation, Interpretation and Discussion}

Two hundred and seventy-four (274) respondents were involved in the study. This was made up of kindergarten teachers from two selected district: Gomoa West District and Cape Coast Metropolitan. However, 10 of the questionnaires could not be retrieved. Therefore, the analysis and discussion were based on the data provided by 264 respondents. Data on background characteristics of kindergarten teachers indicated that they possessed various kinds of professional qualifications. Kindergarten teachers had gone through varying programmes that qualified them as professional kindergarten teachers. It ranged from certificate in preschool education to Masters in education. The data showed that more than half (50.7\%) of teachers had training in basic education whiles $44.7 \%$ have certificates in preschool education, diploma and degree in early childhood education. This confirmed existing data that majority of kindergarten teachers are para-professionals; they are professional teachers but not qualified to teach at the kindergarten by virtue of their training. It was also evident that majority of the teachers were females which is consistent with both global and national statistics.

In summary, the background information revealed that a large number of the kindergarten teachers are females and most of them were youthful. Majority of the kindergarten teachers have qualifications in basic education which does not make them professionally qualified to teach at the kindergarten level. Finally, more than half of the kindergarten teachers have been teaching for less than 9 years.

\section{Kindergarten Teachers' Developmentally Appropriate Practice Beliefs}

Table 1 presents kindergarten teachers responses on the extent to which they belief they will be able to employ developmentally appropriate practices. The 12 items were generated from the principles of developmentally appropriate practice. Interpretation of responses was rendered using means and mean ranges to determine the direction of responses. The mean ranges are:

Mean Ranges: SD: 1.00-1.59 D: 1.60-2.59 A: 2.60-3.59 SA: 3.60-4.00

Table 1: Kindergarten Teachers' Developmentally Appropriate Practice Beliefs

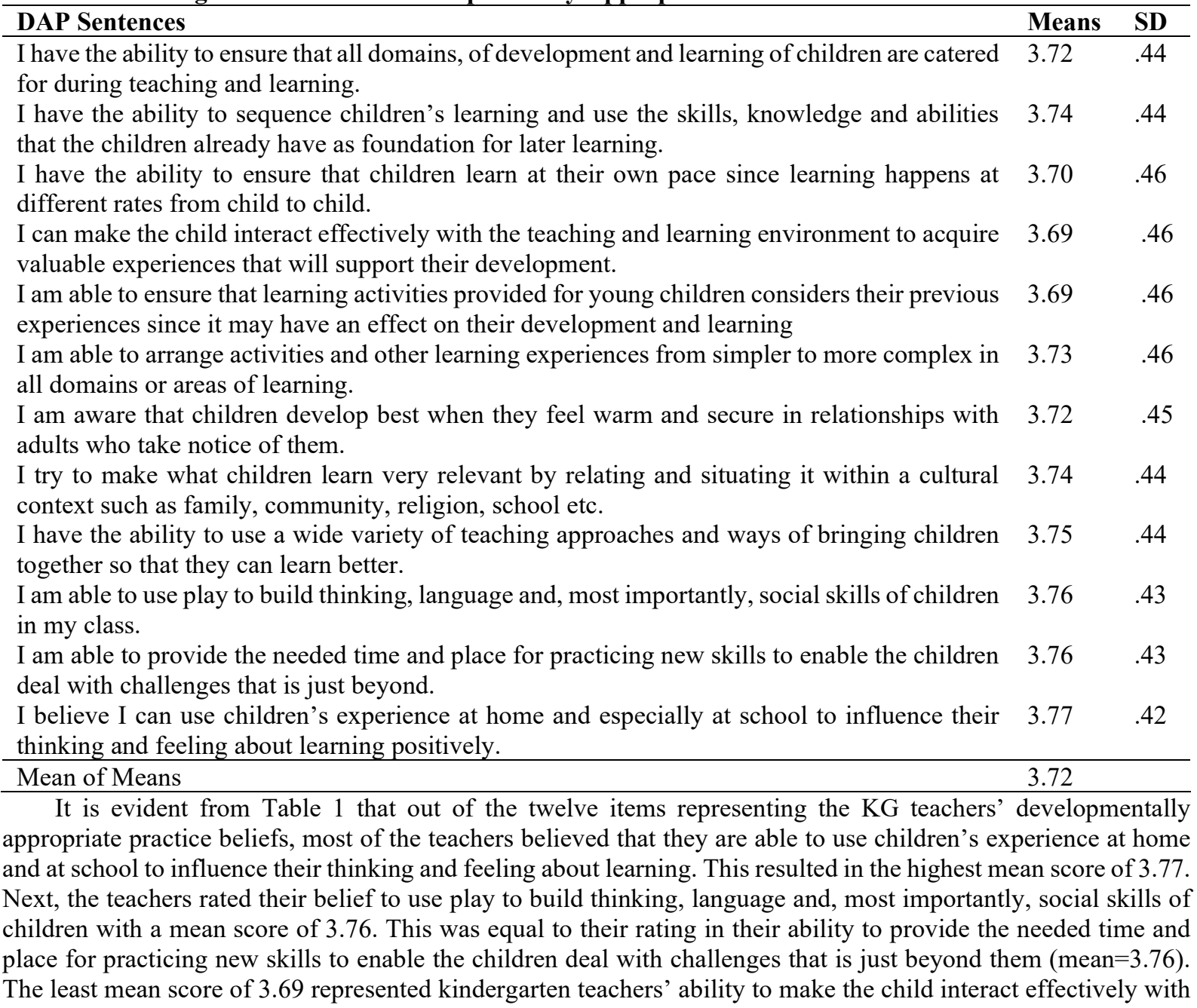


the teaching and learning environment to acquire valuable experiences that will support their development, as well as their ability to ensure that learning activities provided for young children considers their previous experiences since it may have an effects on their development and learning. Generally, the responses of the KG teachers showed a strong belief in their ability to apply developmentally appropriate practices in KG classrooms. This is implied by the grand mean of 3.73 which falls within 3.60-4.00.

\section{Relationship between kindergarten teachers' self-efficacy and their DAP}

This section provides data on the relationship between KG teachers' self-efficacy and their developmentally appropriate practice beliefs. Data was analysed using the Pearsons Product Moment Correlation Coefficient to explore the relationship.

Table 2: Relationship Between Kindergarten Teachers' Self-efficacy and their DAP Beliefs

\begin{tabular}{|c|c|c|c|}
\hline Variables & & $\begin{array}{c}\text { Total self- } \\
\text { efficacy }\end{array}$ & $\begin{array}{r}\text { Developmentally } \\
\text { Appropriate Practice } \\
\text { (DAP) }\end{array}$ \\
\hline \multirow[t]{3}{*}{ Total self-efficacy } & Pearson Correlation & 1 & .183 \\
\hline & Sig. (2-tailed) & & .000 \\
\hline & $\mathrm{N}$ & 264 & 264 \\
\hline \multirow[t]{3}{*}{ Developmentally Appropriate Practice } & Pearson Correlation & $.183^{* *}$ & 1 \\
\hline & Sig. (2-tailed) & .003 & \\
\hline & $\mathrm{N}$ & 264 & 264 \\
\hline
\end{tabular}

Correlation is significant at the 0.01 level (2-tailed).

The relationship between KG teachers' self-efficacy and their use of developmentally appropriate practice beliefs was examined using Pearsons Product Moment correlation coefficient. As revealed in Table 2, there was a small positive statistically significant correlation between self-efficacy of KG teachers and their developmentally appropriate practice beliefs $(\mathrm{r}=.183, \mathrm{n}=264, \mathrm{p}=.003)$. The corresponding $\mathrm{p}$-value implies that the correlation observed between the variables is not due to chance since it is significant $(p \leq .003)$, and thus, there exist a relationship between self-efficacy and developmentally appropriate practice beliefs. The coefficient of determination computed indicates that self-efficacy explains only $3.34 \%$ of the variance in developmentally appropriate practice beliefs.

\section{How Self-efficacy sub-variables Predict Developmentally Appropriate Practice Beliefs}

The third research question explored the extent to which the self-efficacy sub-variables: learner engagement, instructional strategies and classroom management: predicted developmentally appropriate practice beliefs of kindergarten teachers.

Table 3: Combined effect and contribution of self-efficacy subscales on DAP beliefs

\begin{tabular}{|c|c|c|c|c|c|c|c|c|}
\hline Model & $\begin{array}{l}\text { Sum of } \\
\text { squares }\end{array}$ & Df & $\begin{array}{c}\text { Mean } \\
\text { squares }\end{array}$ & $\mathrm{f}$ & Sig & $\mathrm{R}$ & $\mathrm{R}^{2}$ & $\begin{array}{c}\text { Adjusted } \\
\mathrm{R}^{2}\end{array}$ \\
\hline Regression & 32.78 & 4 & 10.93 & 4.53 & .004 & .223 & .050 & .039 \\
\hline Residual & 627.18 & 260 & 2.41 & & & & & \\
\hline Total & 659.97 & 264 & & & & & & \\
\hline Predictors & $\mathrm{B}$ & $\begin{array}{l}\text { Standard } \\
\text { error }\end{array}$ & $\begin{array}{l}\text { Beta } \\
(\beta)\end{array}$ & $\mathrm{t}$ & & $\begin{array}{c}\text { Sig } \\
\text { (p- } \\
\text { value) }\end{array}$ & \multicolumn{2}{|c|}{$\begin{array}{c}\text { Correlation } \\
\text { part }\end{array}$} \\
\hline (Constant) & 34.094 & 2.942 & & 11.589 & & .000 & & \\
\hline $\begin{array}{c}\text { Learner } \\
\text { engagement }\end{array}$ & .038 & .046 & .051 & .834 & & .405 & & .050 \\
\hline $\begin{array}{c}\text { Instructional } \\
\text { strategies }\end{array}$ & .210 & .073 & .174 & 2.866 & & .004 & & .173 \\
\hline Classroom & .150 & .083 & .112 & 1.825 & & 069 & & .110 \\
\hline
\end{tabular}

management

It may be deduced from the data that three self-efficacy sub-variables (learner engagement, instructional strategies and classroom management) when combined have a significant effect on KG teachers' DAP beliefs F $(3,260)=4.53 ; \mathrm{p}<0.05$. The joint prediction $(\mathrm{R}=.223)$ accounted for $5.0 \%$ of the total variance of $\mathrm{KG}$ teachers' DAP beliefs. It may also be inferred that the three variables made varying contributions to the prediction of teachers' DAP. Kindergarten teachers' self-efficacy in instructional strategies made the greatest significant contribution $(\beta$ $=.174 ; \mathrm{t}=2.866 ; \mathrm{p}<0.05)$ to predicting their DAP beliefs. It therefore explained $3.0 \%$ of the total DAP while classroom management $(\beta=.112 ; \mathrm{t}=1.825 ; \mathrm{p}<0.05)$, contributed only $1.2 \%$ to the explanation of variance in DAP beliefs. It thus implies that $95 \%$ of KG teachers' belief in their ability to use DAP can be attributed to other variables other than their self-efficacy. 


\section{Findings and Discussion}

It may be gleaned from the foregoing that, $\mathrm{KG}$ teachers in Central Region strongly agreed that they have the ability to use developmentally appropriate practices in kindergarten classrooms and there is also a positive correlation between KG teachers' self-efficacy and their developmentally appropriate practices beliefs in kindergarten learning settings. The combined total self-efficacy accounted for 5.0\% in the use of DAP while KG teachers' selfefficacy in instructional strategies made the highest contribution of $3.0 \%$.

The results showed that KG teachers beliefs in the use of developmentally appropriate practices was high. Their position underscores Kumtepe's (2005) notion that developmentally appropriate practices utilizes an approach to the education of young children that focuses on the child as a developing human being and life-long learner. The kindergarten teachers overwhelming agreement on the role of DAP in developing all domains of the child is also in sync with Copple and Bredekamp's (2009) assertion that DAP provides the physical, social, emotional, and cognitive needs of children. The foregoing accentuates the view that development is interactive and interrelated. As a result, as young children are given the opportunity to engage with the environment as DAP is employed, their social, physical, intellectual, creative and emotional faculties are nurtured. This culminates into a holistic development of the child.

It is evident that kindergarten teachers significantly endorsed an exploration of children's home and environmental experiences, the use of practical and play activities to enable them effectively interact with themselves and the learning environment. This thinking concurs with Shonkoff and Phillips' (2000) stance that where there is a reciprocal relationship children are more likely to have higher levels of brain function because they are always being supported. The probability of positive outcomes increases when children are engaged in reciprocal relationships, thus creating more synapses or connections in the brain. To facilitate children's success therefore teachers must foster positive interactions with children, between children, with families, and with other teachers (Bredekamp \& Copple, 2009). Creating more opportunities for them to interact inures enormously to their benefit. This then brings into sharp focus the significant role a learning milieu plays in the education of a child. With the Reggio Emelia curriculum development approach for instance, the environment is considered as the 'third teacher' because the extent to which a child learns depends on the kind of environment created. The environment created subsequently relies heavily on the extent to which teachers draw on the relevant experiences of learners to provide engaging familiar opportunities that would promote learning for children from diverse backgrounds.

The hypothesis tested proved that teachers who possessed high self-efficacy are most likely to use DAP in their discharge of teaching duties. Having a high self-efficacy implies that teachers have a belief in their ability to explore and go the extra mile in pooling resources to deal with difficult situations. Employing DAP involves the use of age appropriate resources, techniques and strategies to promote learning; being guided by knowledge about child development. The findings therefore suggest that kindergarten teachers' belief that they will be able to employ age appropriate systems to ensure learning in kindergarten settings. This underscores Kaboaglu's (2015) position that self-efficacious teachers are mindful of the total or whole wellness of children and as such try everything within their power to follow the syllabus and even adopt innovative ways other than the traditional teaching skills to ensure pupils have the utmost benefits.

The findings further corroborates Tschannen-Moran and Hoy's (2007) stance that teachers with high efficacy work with learners who are experiencing difficulty and are unmotivated. Also, such teachers try to find better ways of teaching (Ortlieb, 2010) and are able to organise and manage classroom environment (Leu \& Kinzer, 2002). The findings also support the claim of Bruce, Esmonde, Ross, Dookie and Beatty (2010) that teachers with high selfefficacy are more likely to experiment with effective instructional strategies and are also more willing to take risks in their classrooms. Besides, Tschannen-Moran and Hoy (2007) attribute most instructional successes to teacher self-efficacy. They explain that teachers with high self-efficacy exercises greater commitment to teaching, works longer with learners experiencing difficulty and are less critical when learners make mistakes; these are attributes required by teachers of young children, to enable them succeed. Several studies have also shown that individual teachers' self-efficacy and values play a vital role in shaping the goals, instructional techniques and assessment procedures of schools (Hitchens-Smith, Ortlieb, \& Cheek, 2011). It may be deduced from the foregoing that selfefficacy is critical in any teaching and learning endeavour and especially for facilitating learning of young childrenit can thus spell the success or failure of any curriculum implementation (Gorozidis \& Papaioannau, 2011).

\section{Implications for Practice and Recommendations}

In Africa and especially in Ghana, early childhood education has not received the attention it deserves until recently. This has enormously affected perceptions of stakeholders about education of young children, training of early childhood educators and the provision of requisite infrastructure to support the effective implementation of curricula over the years. In 2007, the Government of Ghana introduced policy measures that sought to streamline the early childhood education sector albeit at a very sluggish pace. Thirteen years down the line, much education seem to have taken place about the relevance of investing heavily in early childhood education and its implications for education at higher levels and for the country's development in general. The findings of the study indicated 
that KG teachers highly rated their belief in their ability (self-efficacy) and the belief in their ability to apply of DAP. The assumption therefore is that given the right doses of exposure to current trends and practices and providing needed resources, KG teachers should be able to elevate their beliefs to enable them employ DAP in kindergarten settings.

This assumption is made in the context of research on teachers' beliefs gaining prominence in educational literature because it has become largely accepted that teachers' beliefs may influence practice. Fenstermacher (1986) suggested that if "our purpose and intent are to change the practices of those who teach, it is necessary to come to grips with the subjectively reasonable beliefs of teachers" (p. 174). Bryan (2012) claimed that "the implementation of educational initiatives is compromised," when teachers' beliefs are not in line with the philosophical underpinnings of the reform. Despite the confusion about teachers' beliefs, empirical research provides evidence that beliefs influence teachers' judgments and actions in the classroom (Chant, 2009; Levin, He \& Allen, 2013). Consequently, if teachers' beliefs influence their teaching, and therefore their learners' opportunities to learn, then beliefs should be a central concern of teaching and teacher education (Kagan, 1992; Ammon \& Levin, 1993).

It is therefore expected that early childhood coordinators in district education directorates would liaise with headteachers of basic schools with kindergartens to organize workshops on the principles of developmentally appropriate practices and practical approaches to using these practices to promote teaching and learning of young children in kindergarten settings. Early childhood educators should create communities of practice that would enable them share information and knowledge on current practices in the field so as to become abreast with new trends. This coupled with workshops organized by districts and NGOs in early childhood education will equip practitioners and teachers to enable them develop the belief and confidence required to create an environment, employ resources and strategies to support young learners.

In the long term, teacher education institutions should make the development of pre-service teachers beliefs a central component of their training whiles providing them with relevant experiences since beliefs of teachers evolves. This has hug implications for the kind of teachers produced eventually.

\section{References}

Abroampa, W. K. (2016). Early childhood Educators self-efficacy and the implementation of the kindergarten curriculum in the Central Region of Ghana. Unpublished Doctoral Thesis, University of Ilorin, Nigeria

Abroampa, W. K. (2018). Assessment of Kindergarten Teachers' Use of Learning Activities and Instructional Resources in the Implementation of the Curriculum in Central Region, Ghana. International Journal of Innovative Research and Development, 7 (6): 67-73

Ahktar, M. (2008). What is self-efficacy? Bandura's four sources of efficacy beliefs. Positive Psychology UK. Retrieved from htt://positive psychology.org.uk/self - efficacy -definition-bandura-meaning?

Allen, L. \& Kelly, B. B. (2015). Transforming the workforce for children Birth through Age 8: A unifying foundation. Washington, D.C.: The National Academies Press.

Ammon, P. A., \& Levin, B. B. (1993). Expertise in teaching from a developmental perspective: The Developmental Teacher Education program at Berkeley. Journal of Learning and Individual Differences, 5, 319-326. doi:10.1016/1041-6080(93)90015-K

Bandura, A. (1977). Self-efficacy: Toward a unifying theory of behavioral change. Psychological Review, 84(2), $191-215$

Bandura, A. (1986). Social foundations of thought and action: A social cognitive theory Prentice Hall, Inc, Englewood Cliffs, NJ

Bandura, A. (1996). Ontological and epistemological terrains revisited, Journal of Behavior Therapy and Experimental psychiatry, 27, 323-345.

Bandura, A. (2006). Guide for constructing self-efficacy scales. Self-efficacy beliefs of adolescents, 5(1), 307-337.

Bartels, E.K. (2004). Training of kindergarten teachers in Ghana: A look to the future. Ghana Education and Teaching. Winneba: University of Education, Winneba.

Basikin, M. (2008). Self-efficacy beliefs of junior secondary English teachers in yogyakarta province of Indonesia. Unpublished Master of Education dissertation. Monash University, Australia.

Boateng, P \& Sekyere, O. F. (2017). Exploring In-service teachers' Self-efficacy in the Kindergarten Classrooms in Ghana. International Journal of Instruction, Vol.11, No.1, pp 239-254.

Bredekamp S. (2000). Play and school readiness. Educational perspectives, 38(1), 18 - 26

Bredekamp, B. \& Copple, J .A. (1997). Empowerment as a function of contextual self-understanding: The effect of work interest profiling on career decision self-efficacy and work locus odef control. Rehabilitation Counseling Bulletin, 51(2), 96-106.

Bredekamp, S., \& Copple, C. (2009). Developmentally appropriate practice in early childhood programs. Washington DC: National Association for the Education of Young Children.

Bruce, C. D., Esmonde, I., Ross, J., Dookie, L., \& Beatty, R. (2010). Teaching and Education: An International 
Journal of Research and Studies, 26(8), 1598-1608.

Bryan, L. A. (2012). Research on science teachers' beliefs. In B. J. Fraser, K. Tobin \& C. J.

McRobbie (Eds.). Second International Handbook of Science Education (Vol. 1, 477- ). Dordrecht: Springer

Chant, R. H. (2009). Developing involved and active citizens: The role of personal practical

theories and action research in a standards-based social studies classroom. Teacher Education Quarterly, 36, 181190. Retrieved May 4, 2014, from http://www.jstor.org/stable/23479208 C

Cochran M., Eds (2007) Early childhood education: An international Encyclopedia. Journal of Early childhood Teacher Education. 28(4) pp, 411-412

Copple, C., \& Bredekamp, S. (2009). Developmentally appropriate practice in early childhood programs serving children from birth through age 8. National Association for the Education of Young Children. $1313 \mathrm{~L}$ Street NW Suite 500, Washington, DC 22205-4101.

Fenstermacher, G. D. (1986). Philosophy of research on teaching: Three aspects. In W. C. Wittrock (Ed). Handbook of research on teaching (3rd ed., pp. 37-49). New York: Macmillan.

Gbate, G. (20011). Lowering standard of education. The Ghanaian Times p.6.

Gestwicki, C. (2007). Developmentally appropriate practice: Curriculum and development in early education. Cengage Learning.

Goffin, D. \& Wilson, F. (2001). Linking Cognition and Literacy in Students with Autism Spectrum Disorder. TEACHING Exceptional Children, 43(6), 54-62.

Gorozidis, G. \& Papaioannou, A. (2011). Teachers' self-efficacy, achievement goals, attitudes and the new Greek physical education curriculum. European Physical Education Review, 17, 231-253.

Hitchens-Smith, C., Ortlieb, E., \& Cheek, E. H. (2011). Perceptions of struggling readers in a developmental reading course. Global Education, 2011 (1), 2-24

Hoy, A. W. (2000) Changes in teacher efficacy during the early years of teaching. Paper presented at the Annual Meeting of the American Educational Research Association, New Orleans.

Kabaoğlu, K. (2015).Predictors of curriculum implementation level in elementary mathematics education: mathematics-related beliefs and teacher self-efficacy beliefs. Unpublished Msc. thesis. Middle East Technical University

Kagan, D. (1992). Implications of research on teacher belief. Educational Psychologist, 27 (1), 65-90. doi:10.1207/s15326985ep2701 6

Kostelnik, D. S., Soderman, O. \& Whiren, A. (2004). Another look at what young children should be learning. Retrieved November 2, 2004, from http://ceep.crc.uiuc .edu/eecearchive/digests/1999/katzle99.html

Kumtepe, A. T. (2005). Effects of Developmentally Appropriate Practices on Children's Reading Development from Kindergarten through Third Grade.

Leu, D., \& Kinzer, C. (2002). Effective literacy instruction-K-8 (5th ed). New York:

Prentice-Hall.Losardo, A., \& Notari-Syverson, A. (2001). Alternative Approaches to Assessing Young Children. Maryland, USA: Paul H. Brookes Publishing Co.

Lenroot, R. K. \& Giedd, J. N. (2006). Brain development in children and adolescents: Insights from anatomical magnetic resonance imaging. Neuroscience Biobehav Rev. 30:718-729

Levin, B. B., He, Y., \& Allen, M. H. (2013). Teacher beliefs in action: A cross-sectional, longitudinal followup study of teachers' personal practical theories. Teacher Educator, 48 (3), 1-17. doi:10.1080/08878730. 2013.796029

NAEYC (2009) NAEYC early childhood program standards and accreditation criteria and guidance for assessment.

Ortlieb, E. (2010). Beyond just books: Sparking students' interest in reading. International Journal of Education, 2(2), E9.

Shonkoff, A. \& Phillips, M, J. (2000). Self-efficacy: The exercise of control. New York: Freeman.

Tschannen-Moran, S. \& Hoy, A. (2007). Cross-cultural infant care and issues of equity and social justice. Contemporary Issues in Early Childhood, 2, 368-371. 